recognition of the social model of disability as it relates to participation by pursuing in-depth analysis to enable the modification of environmental factors, as opposed to tar- geting changes at the individual level. It provides an opportunity to find beauty in environments where young people can thrive and participate fully.

\title{
REFERENCES
}

1. Anaby D, Hand C, Bradley L, et al. The effect of the environment on participation of children and youth with disabilities: a scoping review. Disabil Rehabil 2013; 35: 1589-98.

2. Shikako-Thomas K, Lach L, Majnemer A, Nimigon J, Cameron K, Shevell M. Quality of life from the perspective of adolescents with cerebral palsy: "I just think I'm a normal kid, I just happen to have a disability". Qual Life Res 2009; 18: 825-32.

3. King G, Rigby P, Batorowicz B, et al. Development of a direct observation Measure of Environmental Qualities of Activity Settings (MEQAS). Dev Med Child Neurol 2014; 56: 763-69.

\footnotetext{
4. Dickinson HO, Colver AF. Measurement of the environment of people with disabilities. Arch Phys Med Rebabi 2010; 91: 1310-1.

5. Coster W, Law M, Bedell G, Khetani M, Cousins M, Teplicky R. Development of the participation and environment measure for children and youth: conceptual basis. Disabil Rehabil 2012; 34: 238-46.
}

\section{Movement quality: is beauty only in the eyes of the beholder?}

\section{BERT STEENBERGEN ${ }^{1,2}$ \\ 1 Behavioural Science Institute, Radboud University Nijmegen, Nijmegen, the Netherlands. 2 School of Psychology, Australian Catholic University, Melbourne, Vic., Australia.}

doi: $10.1111 /$ dmcn.12429

This commentary is on the original article by Wright et al. on pages 770-778 of this issue.

Being part of society is an essential aspect of life. Participation is one of the key features in the International Classification of Functioning, Disability and Health: Children and Youth Version model of the World Health Organization. ${ }^{1}$ For children with a compromised motor control disorder such as cerebral palsy (CP), participation in different aspects of society is not a trivial matter. ${ }^{2}$ Often, their compromised motor abilities affect a multitude of movement activities, in turn hindering participation. Essentially, motor control is not only related to what a child 'can do', but also to 'how a child does it'. It is particularly this latter, often neglected, aspect of motor control that is the main focus of the paper of Wright et al. ${ }^{3}$ They have developed and tested an assessment tool (the Quality Function Measure) aimed at measuring the 'aesthetics' of movements in a reliable and valid way, thus focusing on quantifying 'how a child does it'. Although it may not be that obvious at first hand, this may provide an important step towards facilitation of participation in this group of children.

Why should we be concerned with movement quality, or loosely stated, movement aesthetics? If we take a side step to sports science this becomes immediately evident. Although the Olympic motto 'Citius, Altius, Fortius' refers to measurable quantities (seconds, centimeters, kilograms), some sports are rated by their aesthetic quality, such as gymnastics. Clearly, winning (or, participating in the Olympics) is not only about functional skills and excelling in these, but it is also about how aesthetically well these skills are performed. While knowing the winner in sports that have clear measurable units (e.g. seconds, centimeters, kilograms) is straightforward, it becomes more complex when the aesthetic aspects need to be rated. Obviously, there exists no objective quantification of aesthetic quality, and therefore it is left to professional eye of the judges. Identifying the quality, or aesthetics, of movements into an objective measurement system is exactly the purpose of the paper by Wright et al. With this, they encounter a real challenge of quantifying something that may not completely allow quantification.

Still, the need for such quantification is also obvious from a participation point of view. Proficiency in motor skill is an important factor for participation and this not only involves the functional aspect of the skill, but also, and maybe even more so, how these skills are performed as participation is closely related to the (ap) perception of significant others. Once again, this can be illustrated through participation in sports. Studies on participation in sports activities in children with developmental coordination disorder (DCD) and CP have revealed barriers to participation. ${ }^{4,5}$ One notable barrier in children with DCD was the lack of smooth coordination and concomitant lack of confidence. This aspect hindered participation in sports activities.

From these examples it is clear that, in the long run, participation for children with CP (and DCD) might be helped by not only improving their motor function, as is common rehabilitation practice, but also by targeting their movement quality. The development of an appropriate assessment tool and subsequent testing of its reliability and validity is a necessary and valuable first step in this process. Eventually, beauty may then not only be in the eyes of the beholder. 


\section{REFERENCES}

1. World Health Organization. International Classification of Functioning, Disability and Health: Children and Youth Version (ICF-CY). Geneva: WHO, 2007.

2. Imms C. Children with cerebral palsy participate: a review of the literature. Disabil Rehabil 2008; 30: 1867-84. 3. Wright FV, Rosenbaum P, Fehlings D, Mesterman R, Breuer U, Kim M. The Quality Function Measure: reliability and discriminant validity of a new measure of quality of gross motor movement in ambulatory children with cerebral palsy. Dev Med Child Neurol 2014; 56: $770-78$.

4. Barnett AL, Dawes H, Wilmut K. Constraints and facilitators to participation in physical activity in teenagers with Developmental Co-ordination Disorder: an explorative interview study. Child Care Health Dev 2013; 39: 393-403.

5. Bult MK, Verschuren O, Lindeman E, et al. Predicting leisure participation of school-aged children with cerebral palsy: longitudinal evidence of child, family and environmental factors. Child Care Health Dev 2013; 39: 374-80.

\section{Providing a population-based perspective on the perinatal factors associated with cerebral palsy}

\author{
RUSSELL S KIRBY \\ Department of Community and Family Health, College of Public Health, \\ University of South Florida, Tampa, FL, USA. \\ doi: $10.1111 / \mathrm{dmcn} .12465$
}

This commentary is on the original article by Trønnes et al. on pages 779-785 of this issue.

Population-based data on developmental disabilities are hard to come by, even in the age of electronic medical records and clinical informatics. It is hard to understand why such registries for cerebral palsy (CP), epilepsy, and autism spectrum disorders do not already exist; it is much easier to argue why they are needed. The fact remains that prospectively collected longitudinal data on these conditions are essential to furthering our understanding of their etiology, risk factors, natural history, treatment, and longterm outcomes.

The study by Trønnes et al. ${ }^{1}$ examines the role of perinatal risk factors in CP among all live-born infants in Norway during the 35-year period from 1967 to 2001. This paper makes the case for the value of populationbased registries and health information systems clearly and concisely. These data do have some limitations: most notably missing data, potential under-reporting of complications and conditions affecting pregnancy, and some under-identification of milder cases of CP. But these limitations are counterbalanced by the internal consistency of the findings, more than three decades of data included in the analysis, and prior validation studies that calibrate the sensitivity and specificity of the diagnosis of CP as well as other pregnancy outcomes. ${ }^{2,3}$

The sad fact remains that even in much of the developed world, there are very few data repositories with which to compare the findings of Trønnes et al., ${ }^{1}$ and elsewhere data are even sparser. In the United States, for example, many researchers continue to use the half-century old Collaborative Perinatal Project, which had an effective sample size approximately equivalent to an annual birth cohort in Norway today; ${ }^{4}$ while the four-site Autism and Developmental Disabilities Monitoring Network data are collected from a population of children at age 8 years and include limited data for analysis of perinatal risk factors. ${ }^{5}$ But there are signs of change - all payer claims databases are beginning to emerge, organized across insured lives in health plans or across states in the United States. These data hold some promise for research into both risk factors for $\mathrm{CP}$ and health services utilization and outcomes. ${ }^{6}$ Even if these resources were available today, however, it would take considerable time to accumulate data covering more than a generation of pregnancies for a defined population.

As a perinatal and paediatric epidemiologist with a longstanding interest in the health and health care of children with birth defects and developmental disabilities, it is my hope that researchers focused on CP might take advantage of the opportunity afforded by the linkage of the national registries used by Trønnes et al. ${ }^{1}$ This would advance a research agenda focused on co-occurring disabilities and other health conditions, mobility and functioning, and child well-being in Norway or other countries with similar population health informatics resources. While these databases have limitations, when used with care we can still advance knowledge; researchers may even quantify these limitations and enable data quality improvement strategies to address those that can be controlled. These opportunities await those intrepid enough to answer the call.

\section{REFERENCES}

1. Trønnes H, Wilcox AJ, Lie RT, Markestad T, Moster D. Risk of cerebral palsy in relation to pregnancy disorders and preterm birth: a national cohort study. Dev Med Child Neurol 2014; 56: 779-85.
2. Thomsen LC, Klungsøyr K, Roten LT, et al. Validity of the diagnosis of pre-eclampsia in the Medical Birth 